Implications for interpretation of $\mathrm{C} / \mathrm{N}, \delta^{13} \mathrm{C}$ and $\delta^{15} \mathrm{~N}$ values

Bias by acid pre-treatment on OM can significantly undermine $\mathrm{C} / \mathrm{N}$ values as indicators of OM provenance. For example, Figures 1 and 2 show that although broccoli (Brassica oleracea) is a terrestrial $C_{3}$ plant, an aquatic or aquatic/terrestrial combination could be concluded from the data, depending upon the method and/or acid reagent (see Brodie et al., 2011a). In addition, $\mathrm{C} / \mathrm{N}$ values can also vary considerably depending on whether they are calculated with $\% \mathrm{~N}$ from treated or untreated sample aliquots (see Brodie et al., 2011a, b). For $\delta^{13} \mathrm{C}$, biasing in the range of $0.2-7.1 \%$ o can undermine $C_{3}$ vs. $C_{4}$ plant type interpretations, and together with $\mathrm{C} / \mathrm{N}$ undermine bi-plot interpretations of $\mathrm{C} / \mathrm{N}, \delta^{13} \mathrm{C}$ and $\delta^{15} \mathrm{~N}$ values. This clearly demonstrates that the data are inherently unreliable as a function of the analytical approach. Although the underlying mechanisms require further research, it is clear the biases represented here across a range of terrestrial and aquatic, modern and ancient or- ganic materials has direct implications for paleo reconstructions: understanding and reducing the uncertainty on the data is an essential prerequisite for reliable interpretations and reconstructions.

\section{Concluding Remarks}

The systematic comparisons of Brodie et al. (2011a, b) clearly demonstrate nonlinear and unpredictable biasing of OM due to acid pre-treatment, and concomitantly indicate that complete IC removal (the purpose of acid pre-treatment) is not guaranteed. It is concluded that these biases are inherently not correctable but inevitable, and have a direct consequence for the accuracy and precision of measured values (i.e., significantly greater than instrument precision). Moreover, environmental interpretations of the data in both modern and paleo systems could be highly questionable.

\section{Acknowledgements}

The author is grateful to J. Casford, J. Lloyd, Z. Yongqiang, T. Heaton, M. Bird and M. Leng for their support and discussions. Financial support came from the NERC through PhD studentship (NE/F007264/1), a NERC isotope Facility grant (IP/1165/0510), and the Dudley Stamp Memorial Fund.

\section{References}

Brodie, C.R., Leng, M.J., Casford, J.S.L., Kendrick, C.P., Lloyd, J.M., Zong, Y.Q. and Bird, M.I., 2011a: Evidence for bias in C and N concentrations and $d^{13} \mathrm{C}$ composition of terrestrial and aquatic organic materials due to pre-analysis acid preparation methods, Chemical Geology, 282: 67-83.

Brodie, C.R., Heaton, T.H.E., Leng, M.J., Kendrick, C.P., Casford, J.S.L. and Lloyd, J.M. 2011b: Evidence for bias in measured $d^{15} \mathrm{~N}$ values 0 terrestrial and aquatic organic materials due to pre-analysis acid treatment methods, Rapid Communications in Mass Spectrom etry, 25: 1089-1099.

Kennedy, P., Kennedy, H. and Papadimitriou, S., 2005: The Effect of acidification on the determination of organic carbon, total nitrogen and their stable isotopic composition in algae and marine sediment, Rapid Communication in Mass Spectrometry, 19: 10631068.

Meyers, P.A., 2003: Applications of organic geochemistry to palaeolimnological reconstructions: a summary of examples from the Laurentian Great lakes, Organic Geochemistry, 34: 261-289.

Sampei, Y. and Matsumoto, E., 2008: C/N ratios in a sediment core from Nakaumi Lagoon, southwest Japan, Usefulness as an organic source indicator, Geochemistry Journal, 35(3): 189-201.

For full references please consult:

http://www.pages-igbp.org/products/newsletters/ref2011_2.pdf

\title{
Extending glacier monitoring into the Little Ice Age and beyond
}

\author{
Michael Zemp ${ }^{1}$, H.J. ZumbühL ${ }^{2}$, S.U. Nussbaumer ${ }^{1,2}$, M.H. Masiokas ${ }^{3}$, L.E. Espizua ${ }^{3}$ and P. Pitte ${ }^{3}$ \\ 'World Glacier Monitoring Service, Department of Geography, University of Zurich, Switzerland; michael.zemp@geo.uzh.ch \\ ${ }^{2}$ Institute of Geography and Oeschger Centre for Climate Change Research, University of Bern, Switzerland; ${ }^{3}$ Argentine Institute of Snow Re- \\ search, Glaciology and Environmental Sciences, (IANIGLA), CCT-CONICET Mendoza, Argentina
}

\section{Reconstructions of glacier front variations based on well-dated historical evidence from the Alps, Scandinavia, and the southern Andes, extend the observational record as far back as the $16^{\text {th }}$ century. The standardized compilation of paleo-glacier length changes is now an integral part of the internationally coordinated glacier monitoring system.}

Glaciers are sensitive indicators of climatic changes and, as such, key targets within the international Global Climate Observing System (GCOS, 2010). Glacier dynamics contribute significantly to global sea level variations, alter the regional hydrology, and determine the vulnerability to local natural hazards. The worldwide monitoring of glacier distribution and fluctuations has been well established for more than a century (World Glacier Monitoring Service, 2008). Direct measurements of seasonal and annual glacier mass balance, which are available for the past six decades, allow us to quantify the response of a glacier to climatic changes. The variations of a glacier front position represents an indirect, delayed, filtered and enhanced response to changes in climate over glacierspecific response times of up to several decades (Jóhannesson et al., 1989; Haeberli and Hoelzle, 1995; Oerlemans, 2007).
Regular observations of glacier front variations have been carried out in Europe and elsewhere since the late $19^{\text {th }}$ century. Information on earlier glacier fluctuations can be reconstructed from moraines, early photographs, drawings, paintings, prints, maps, and written documents. Extensive research (mainly in Europe and the Americas) has been carried out to reconstruct glaciers fluctuations through the Little Ice Age (LIA) and Holocene (e.g., Zumbühl, 1980; Zumbühl et al., 1983; Karlén, 1988; Zumbühl and Holzhauser, 1988; Luckman, 1993; Tribolet, 1998; Nicolussi and Patzelt, 2000; Holzhauser et al., 2005; Nussbaumer et al., 2007; Zumbühl et al., 2008; Masiokas et al., 2009; Nesje, 2009; Holzhauser, 2010; Nussbaumer and Zumbühl, 2011). However, the majority of the data remains inaccessible to the scientific community, which limits the verification and direct comparison of the results. In this article, we document our first attempt towards standardizing reconstructed glacier front variations and integrating them with in situ measurement data of the World Glacier Monitoring Service (WGMS).

\section{Standardization and database}

The standardization of glacier front variations is designed to allow seamless comparison between reconstructions and in situ observations while still providing the most relevant information on methods and uncertainties of the individual data series. The standardized compilation of in situ observations is straightforward: the change in glacier front position is determined between two points in time and supplemented by information on survey dates, methods and data accuracies. The reconstruction of paleo-glacier front positions and their dating is usually more complex and based on multiple sources 
of evidence. Spatial uncertainty can arise from ambiguous identification of the glacier terminus, while temporal uncertainty is associated with the dating technique used in each case. A good example is the use of oil paintings, where it is important to distinguish between the time of first draft (e.g., a landscape drawing in the field) and production of the painting itself, which could happen several years later.

The concept of integration of reconstructed front variations into the relational glacier database of the WGMS was jointly developed by natural and historical scientists. The glacier reconstruction data are stored in two data tables. The first table contains summary information of the entire reconstruction series including a figure of the cumulative length changes, investigator information, and references. The second table stores the individual glacier front variation data, minimum and maximum glacier elevation, and metadata related to the reconstruction methods and uncertainties. The metadata are stored in a combination of predefined choices of methods and open text fields. This ensures a standardized description of the data, but also provides space for individual remarks. Both data tables are linked by a unique numeric glacier identifier to the main table of the WGMS database with general information of the present-day glacier. This database relationship enables the direct comparison of reconstructed with observed front variations. Figure 1 shows an example for the Mer de Glace glacier with the sum of available meta-information stored within the database.

\section{Results and discussion}

The WGMS database contains detailed inventory information of about 100,000 glaciers worldwide. In addition, in situ observations of frontal variations of 1,800 glaciers, mass balance data of 230 glaciers, and reconstructed frontal variations of the 26 glaciers mentioned below are now readily available in standardized and digital form. The reconstructed front variations extend the direct observations (mostly from the $20^{\text {th }}$ century) by two centuries in Norway and by four centuries in the Alps and South America. Also available are moraines data back to the mid-Holocene. The direct comparison of long-term reconstructions with in situ observations reveals some striking features (Fig. 2).

The investigated glaciers in the western and central Alps show several periods of marked advances during the LIA, that are similar or even larger than LIA extent around AD 1850. Reconstructions reveal dramatic glacier advances that started in

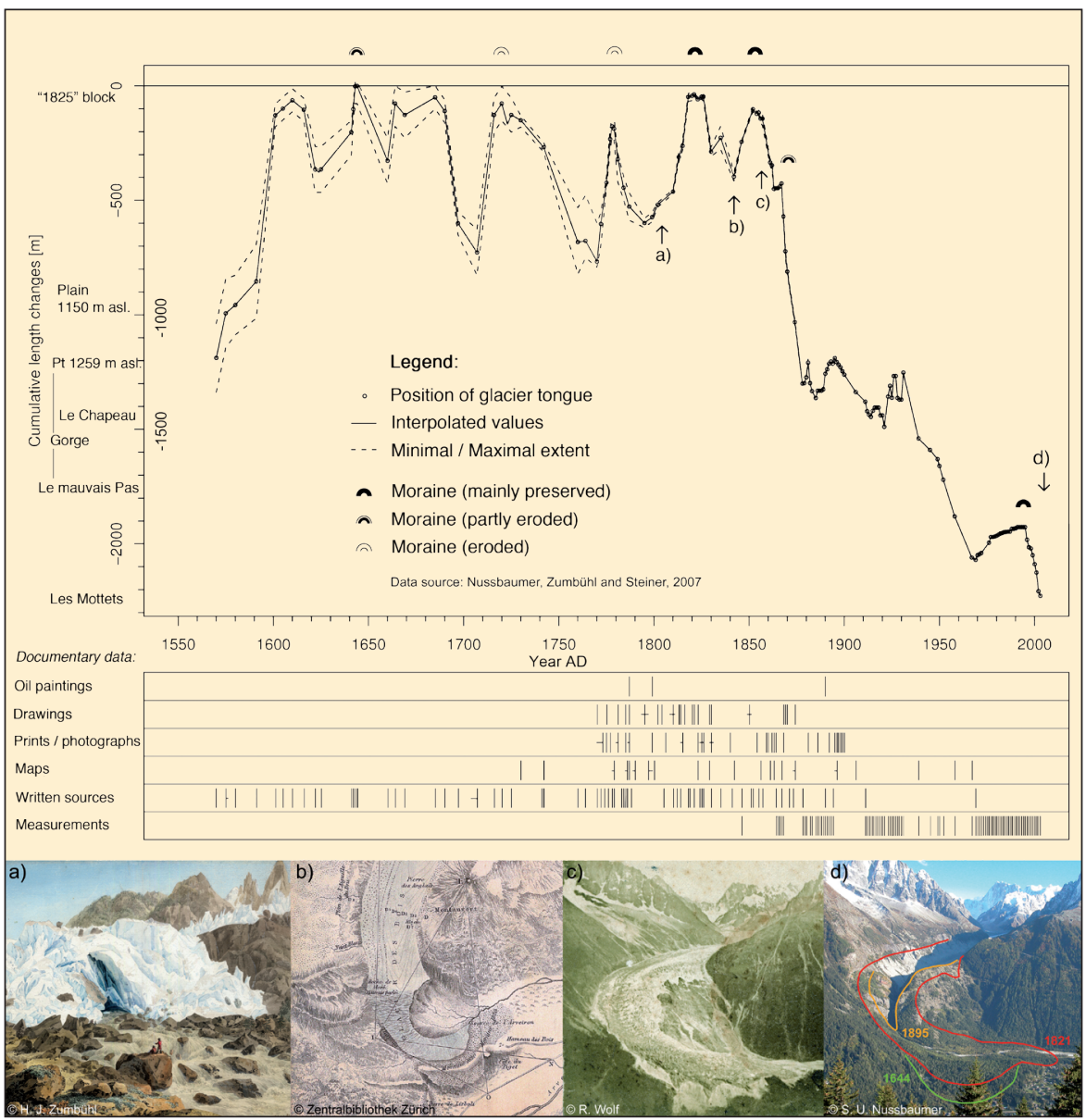

Figure 1: Fluctuations of the Mer de Glace, France, during and following the LIA, reconstructed from a variety of sources (Nussbaumer et al., 2007). Length changes (relative to AD 1644 = maximum of LIA) were derived from documentary data as shown in the compilation below the $x$-axis, where small horizontal lines indicate uncertainties concerning the date of the document. Landmarks are indicated beside the y-axis. In situ measurements for the 1911-2003 period were obtained from the Laboratory of Glaciology and Geophysical Environment in Grenoble. Images a-d:The Mer de Glace (a) in 1804 drawn by Jean-Antoine Linck, (b) in 1842 mapped by James David Forbes, (c) in the 1850s photographed by Henri Plaut, and (d) in 2005 (Nussbaumer et al., 2007).

the late $16^{\text {th }}$ century, overran cropland and hamlets, and reached maximum lengths at ca. AD 1600 and 1640 (Zumbühl, 1980; Nussbaumer et al., 2007; Steiner et al., 2008). Further maxima in glacier extent were reached around AD 1720, 1780, 1820 and 1850. After this last event, the direct measurement series show an impressive glacier retreat of 1-3 km, with intermittent minor re-advances in the 1890s, 1920s and between AD 1965 and 1985.

The historically based reconstructions for glaciers in southern Norway (Nussbaumer et al., 2011; Nesje, 2009) indicate that the maximum glacial extent of the LIA peaked around AD 1750 at Jostedalsbreen and in the late 1870 s at Folgefonna. The reconstructed front variation series of Nigardsbreen (an outlet glacier of Jostedalsbreen) shows that the maximum LIA expansion occurred in AD 1748, and that it was preceded by a period of strong frontal advance that lasted (at least) 3-4 decades. Other sources report devastation of pastures by neighboring glaciers at that time (Nussbaumer et al., 2011). Direct observations at Nigardsbreen and other glaciers in southern Norway reveal a regional pattern of recent intermittent re-advances mainly during the 1990s. It is worthwhile to note that the extent of Nigardsbreen in the $17^{\text {th }}$ century was similar to that of the present day (Nesje et al., 2008), and that the period of glacier re-advances in the 1990s is short (both in time and extension) considering the overall retreat of 1-4 $\mathrm{km}$ since the LIA maximum.

In southern South America, datable evidence for past glacier variations is most abundant in the Patagonian Andes. Despite recent efforts in this region and in other Andean sites to the north (Espizua, 2005; Espizua and Pitte, 2009; Jomelli et al., 2009; Masiokas et al., 2009), the number of chronologies of glacier fluctuations prior to the $20^{\text {th }}$ century is still limited. In the southern Andes, most records indicate that glaciers were generally more extensive prior to the $20^{\text {th }}$ century, with dates of maximum expansion ranging from the $16^{\text {th }}$ to the $19^{\text {th }}$ centuries. Based on the available evidence, Glaciar Frías (northern Patagonian Andes) probably contains the best-documented history of fluctuations since the LIA in southern South America, covering the period between AD 16392009. 


\section{Conclusions and outlook}

Reconstructed LIA and Holocene glacier front variations are crucial for understanding past glacier dynamics and enable an objective assessment of the relative significance of recent glacier fluctuations (i.e., $20^{\text {th }}$ and late $19^{\text {th }}$ century changes) in a long-term context. The standardized compilation and free dissemination of reconstructed and in situ observed glacier fluctuation records offer several benefits for both data providers and users. Their incorporation within the international glacier databases guarantees the long-term availability of the data series and increases the visibility of the scientific results (which in historical glaciology are often the work of a lifetime). Furthermore, the database facilitates comparisons between glaciers and between different methods, and opens the field to numerous scientific studies and applications.

As the next steps of this new initiative, we aim to: (1) integrate a greater number
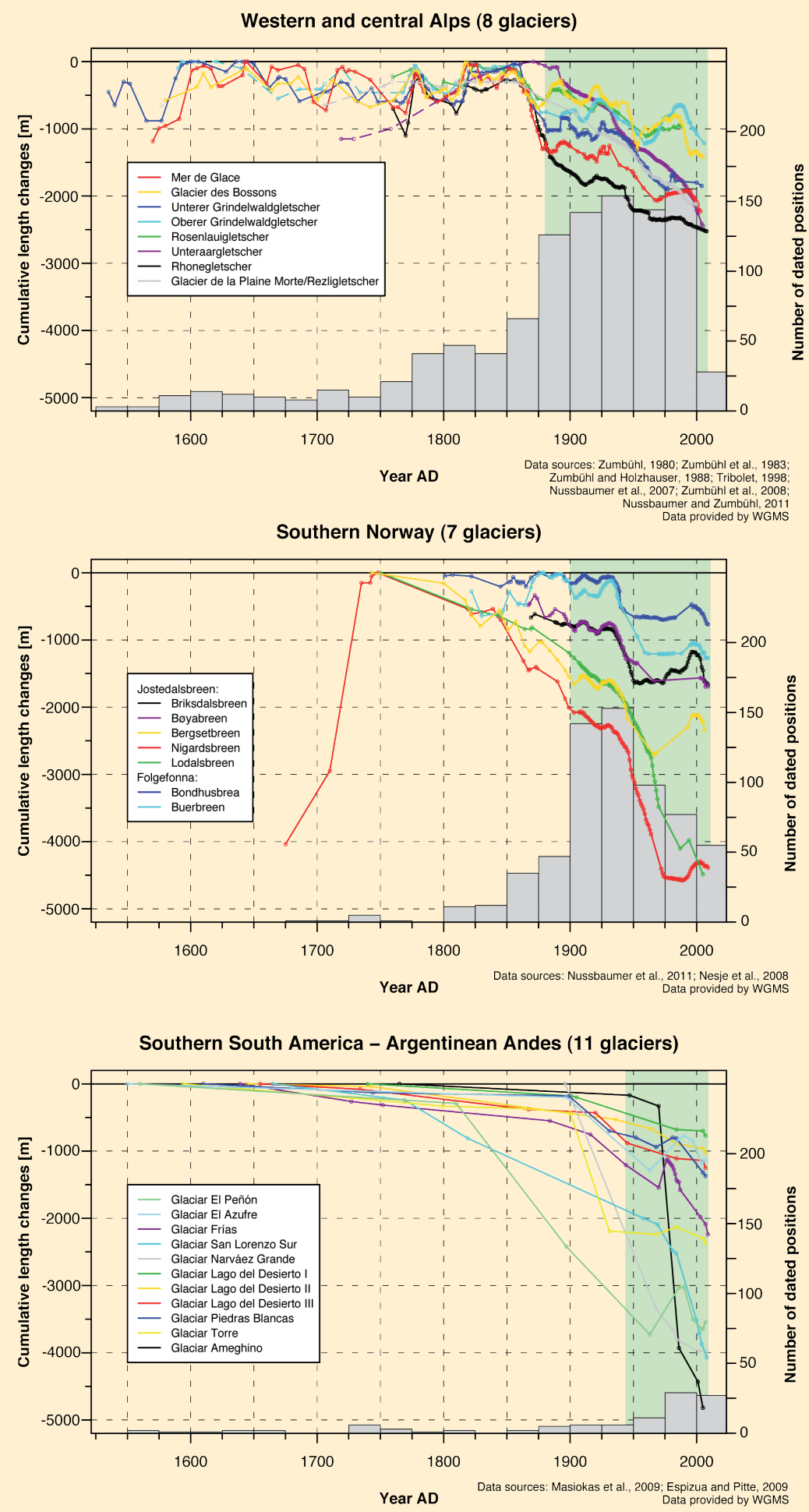

Figure 2: Reconstructed and measured cumulative glacier front variations in the Alps, Norway and southern South America since the Little Ice Age $(L I A)$. The zero value on the y-axis corresponds to the most extensive front position of glaciers during the LIA. The period with direct front measurements is indicated by light green background. Gray vertical bars show the total number of available data for the selected glaciers. Note the significantly lower number of data points available from the Southern Andes. of time series, (2) incorporate records that cover the entire Holocene, and (3) include data from other regions (e.g., the Himalayas, North America). Ideally, the growing new dataset will facilitate collaboration between the glacier monitoring and reconstruction communities and become an additional tool for the comparison of present-day to pre-industrial climate changes. This should eventually result in new scientific findings (e.g., related to the climatic interpretation of past and present glacier fluctuations).

\section{International glacier databases: Requesting and submitting data} Worldwide collection of standardized data on the distribution and changes of glaciers has been internationally coordinated since 1894. Today, the World Glacier Monitoring Service (www.wgms.ch) is in charge of the compilation and dissemination of glacier datasets in close collaboration with the US National Snow and Ice Data Center (www.nsidc.org) and the Global Land Ice Measurement from Space initiative (www.glims.org) within the framework of the Global Terrestrial Network for Glaciers (www.gtn-g.org).

For available data or guidelines on data submission please check these websites and/or contact us directly: wgms@ geo.uzh.ch

\section{Acknowledgements}

We are grateful to Wilfried Haeberli and Heinz Wanner for their valuable assistance. This work has been supported by the Swiss National Science Foundation (grant 200021-116354). The collection and processing of data from Argentinean glaciers was supported by Agencia Nacional de Promoción Científica y Tecnológica (grants PICT02-7-10033, PICT07-03093 and PICTR02-186), and the Projects CRNO3 and CRN2047 from the Inter American Institute for Global Change Research (IAI).

\section{References}

Holzhauser, H., Magny, M. and Zumbühl, H.J., 2005: Glacier and lakelevel variations in west-central Europe over the last 3500 years, The Holocene, 15(6): 789-801.

Masiokas, M.H., Rivera, A., Espizua, L.E., Villalba, R., Delgado, S. and Aravena, J.C., 2009: Glacier fluctuations in extratropical South America during the past 1000 years, Palaeogeography, Palaeoclimatology, Palaeoecology, 281(3-4): 242-268.

Nussbaumer, S.U., Zumbühl, H.J. and Steiner, D., 2007: Fluctuations of the Mer de Glace (Mont Blanc area, France) AD 1500-2050: an interdisciplinary approach using new historical data and neural network simulations, Zeitschrift für Gletscherkunde und Glazialgeologie, 40(2005/2006): 1-183.

WGMS, 2008: Global Glacier Changes: facts and figures, Zemp, M., Roer, I., Kääb, A., Hoelzle, M., Paul, F. and Haeberli, W. (Eds.), UNEP, World Glacier Monitoring Service, Zurich, Switzerland, 88 pp.

Zumbühl, H.J., 1980: Die Schwankungen der Grindelwaldgletscher in den historischen Bild- und Schriftquellen des 12. bis 19. Jahrhunderts. Ein Beitrag zur Gletschergeschichte und Erforschung des Alpenraumes, Denkschriften der Schweizerischen Naturforschenden Gesellschaft (SNG), Band 92. Birkhäuser, Basel/Boston/Stuttgart $279 \mathrm{pp}$.

For full references please consult:

http://www.pages-igbp.org/products/newsletters/ref2011_2.pdf 